\title{
What is advertising without blending? Advertisements in women's magazines
}

\author{
Nihada Delibegović Džanić1 \& Alma Žerić ${ }^{2}$ \\ University of Tuzla ${ }^{1}$ \\ University of Sarajevo ${ }^{2}$
}

\begin{abstract}
Conceptual integration theory, proposed by Fauconnier and Turner in 1993, has been successfully used in the study of a wide range of phenomena of human thought and action, from counterfactuals to metaphors, proving blending to be present in the simplest kinds of human thinking. In that sense, conceptual integration theory has emerged as a powerful theory that can account for a wide variety of linguistic and non-linguistic phenomena. Therefore, it is not surprising that conceptual integration theory has found its application in the study of advertising. Advertising requires both conscious and subconscious mental interpretation of the hidden messages. The primary objective of this paper is to show that conceptual integration theory is equipped with the mechanisms that can explain the construction of the meaning of text-image advertisements. Specifically, analyzing several text-image advertisements in women's magazines, this paper attempts to explore to what extent hidden cognitive mechanisms involved in the interpretation of advertising can be explained using the postulates of conceptual integration theory.
\end{abstract}

Key words: conceptual integration theory; blending; metaphor; advertising.

\section{Introduction}

One cannot fail to notice that advertisements are omnipresent in the contemporary world. The ubiquity of advertisements can be explained in terms of the advent of a variety of print and digital media in the past century. The concept behind advertising is well-known to all members of the contemporary society. Therefore, it is not surprising that scholars and laymen alike recognize that the primary purpose of advertising is to persuade a consumer to buy a product. Text-image advertisements, composed of pictorial and verbal elements, are said to be static in nature. However, in terms of the creation and processing of the meaning of such advertisements, human cognitive processes are far from being static.

In this paper, we analyze text-image advertisements within the framework of conceptual integration theory. The meaning of the advertisements arises in the blended spaces as a result of a series of mental gymnastics performed over the 
conceptual integration networks, producing highly imaginative and humorous blends. The processing of the hidden messages in advertisements is largely unconscious, taking place in the integration network. In addition, we also examine how conceptual integration can contribute to achieving the main goal of advertising, that is, highlighting positive characteristics of a product and affecting our behavior as consumers.

When we consider the sheer amount of advertisements that we encounter every day, it seems almost redundant to explain such a familiarity, since it literally is all around us. In laymen terms, we could say that the basic function of an advertisement is to present a product as desirable to potential buyers. And although some people might deem themselves immune to the tricks used by the advertising companies to promote certain goods and services, the bottom line is that they are highly effective. We are bombarded with advertisements; from our computer screens, TVs and radios, to our streets, newspapers, magazines, etc. This just goes to show that we are living in a highly consumerist world. Karl Marx's words, "that which money can buy, that am I, the possessor of money" ${ }^{1}$ sum up the consumerist nature of the world today, a consumerist culture in which advertisement plays a big role.

An important aspect of advertising, besides promoting products, has always been the power to promote ideas and values, and in such a way create ideologies. This is especially obvious if we take a closer look at the advertisements intended and designed for a specific audience, such as the ones found in women's magazines. Norman Fairclough (2001: 172) identifies the ideological nature of visual advertisement and states, when discussing consumerism, advertising and ideologies, "visual images allow advertising to more easily create worlds which consumers may be led to inhabit, because of the strength of the ideology expressed in the saying that 'the camera doesn't lie'". For an example of this 'candid camera', simply imagine any advertisement for make-up, these are quite common in women's magazines. There is usually a picture of a very attractive woman, with seemingly flawless features, which she has thanks to the fact that she is using a certain product that is being advertised. Ellen McCracken (1993: 71) states that:

The utopian element in ideology helps to assuage discontent with the inequalities of contemporary social organization and facilitates acceptance of the ideological representations as real or natural. In an ad that uses stereotypic gender distinctions to sell a product, for example, elements such as glamor, a sense of sexual transgression, the implicit promise of love and feelings of self-worth, and the aesthetic composition of the ad itself are some of the abstract incentives offered readers to make the stereotypical portrayal palatable and even desirable.

So besides selling the product by making a promise of sorts that the results of using that product will resemble the image used in the advertisement, advertising

\footnotetext{
${ }^{1}$ Karl Marx's writes about this in his "Economic and Philosophic Manuscripts of 1844 - The Power of Money".
} 
companies also exploit the 'ideal' that has been enforced onto women, i.e. that they have to fit a certain mold to be considered beautiful and attractive. This is another ideology present in both the magazines and advertisements within them - the stereotype of a certain type of woman is promoted, leaving out all those who do not fit into that frame, be it physical or behavioral (young, beautiful, fit, successful, etc.).

The advertising industry might have bloomed with the modern age of technology. However, magazines were and still remain one of the most fruitful grounds for advertisements. Glossy publications, such as the highly popular women's magazines, offer a perfect frame for advertising; whereas commercials during our favorite TV show or Internet pop-up ads might be perceived as nuisances, it would be hard to imagine a women's magazine without advertisements. One such magazine is the Cosmopolitan magazine, a magazine sold all over the world. ${ }^{2}$ One section of their Facebook page describes the magazine as the best-selling magazine for young women in the U.S., and call it a bible for fun, fearless females with more than 17 million readers a month. They also claim that Cosmopolitan delivers the latest news on men and love, work and money, fashion and beauty, health, selfimprovement and entertainment. On the surface, this magazine seems to be tailored for the modern woman; it deals with a myriad of topics that could potentially be interesting and even useful. However, referring back to McCracken's stereotype that becomes desirable, a conflict arises here. Joke Hermes (1995: 9) writes:

Part of me can understand why women's magazines continue to inspire concern and criticism in feminist observers. Women's magazines' emphasis on 'woman' and 'femininity', however liberated parts of them have become, remains unsettling, given that they are still overwhelmingly heterosexual in nature and predominantly white in color.

Everyone has an opinion about women's magazines. Some argue that they are not in fact feminist in nature, and yet so many women, from different cultural, racial and ethnical backgrounds, continue to read them. Disregarding the cultural richness of their readership, it seems that women's magazines create a homogenous portray of a modern woman, which is also reflected in advertisements.

\section{Metaphors in advertisements}

Since advertisements are so numerous, for them to be effective, to stand out from the sea of other advertisements, they must be noticed. One very popular strategy that advertisements employ for this purpose, and which is of interest to this study, is the use of metaphors. As Kövecses (2002: 65) noted, "a major manifestation of conceptual metaphors are advertisements." How we interpret these cognitive mechanisms depends not only on our previous knowledge and experience, but

\footnotetext{
${ }^{2}$ In addition to the U.S. flagship, Cosmopolitan publishes 61 print magazine editions around the world.
} 
also on our culture. George Lakoff and Mark Johnson (1980: 22) list this as one of the characteristics of metaphors: "The most fundamental values in a culture will be coherent with the metaphorical structure." However, if we take into consideration the fact that the world has become a global village, some cultural traits have also become globalized. Especially if we look at something like women's magazines, a form that was first popularized in the Anglo-American culture and spread globally in that same form, articles and advertisements alike. David Machin and Theo van Leeuwen (2007) prove this when they analyzed 44 editions of Cosmopolitan from countries around the world to see how these magazines shape gender identity and promote an idea of a fun and fearless woman. Noting some differences, the authors come to a conclusion that all the editions mimic the USA one. For this reason, it might be safe to say that when analyzing metaphors in Cosmopolitan magazines, a specific culture does not play a big role.

Abuczki Ágnes (2009) analysed metaphor use in advertisements in two editions of Cosmopolitan, a USA and a Hungarian one, for the purpose of manipulating the readers in terms of their attitudes towards relationships, health and beauty. Abuczki analyzed the metaphors in seven groups based on their target domain. One of them, besides the most popular metaphor in advertisements where the product is a friend of the buyer, is SEXUAL DESIRE IS HUNGER in which women are represented as tempting food for men. This metaphor that equates women with food has been recognized as one of the most frequent ones (Hines, 1999). This goes to show that the stereotypes still present in advertisements promote an unhealthy image of women as sexual objects or food for men, with their looks closely connected with every other aspect of their lives.

Marisol Velasco-Sacristán and Pedro A. Fuertes-Olivera (2006) also analyze metaphors in Cosmopolitan, the UK edition. Their study is based on a previous study of Velasco-Sacristán from 2003 where the author analyzed 1142 advertisements and made a categorization of gender stereotypes in advertisements. Velasco-Sacristán \& Fuertes-Olivera define metaphors in advertisements as "ideological metaphors in which the conceptual mapping(s) that is (are) projected from the source to the target domain may create and/or reflect some kind of discrimination against men and women" (2006: 119). To use one of their examples, a bra advertisement in which an attractive woman is shown in only her bra with a slogan "I can't cook, who cares?" has several covert sexist messages, e.g. an attractive woman, who fulfills her role of a sexual object, does not necessarily has to fulfill her stereotypical traditional role of a good homemaker and cook. While moving away from the stereotype of a housewife, it transfers a woman into another stereotypical role of an object. And this is a common case; there are two extremes, a woman is represented as either a housewife or a sexual object.

Sirma Oya Tekvar (2008) makes some similar observation in her study of advertisements in Cosmopolitan and FHM. Besides the stereotypical submissive female role, the author also finds a few more modern interpretations of independent 
women. However, women are still objectified through the advertised products and the new identities that they are to create by using these products, whereas man are shown as prizes to be deserved and won (2008: 13). While these advertisements are not openly sexist or discriminatory towards women, the ideologies they promote are - a women without her identity and a man who is necessary and has to be deserved. ${ }^{3}$

\section{Conceptual integration theory}

Conceptual integration theory, or blending theory, proposed by Gilles Fauconnier and Mark Turner, gives insight into many processes of human thought and language. 4 This theory is the theoretical framework for the study. Conceptual integration is defined as "another basic mental operation, highly imaginative but crucial to even the simplest kinds of thought" (Fauconnier \& Turner, 2002: 18). Its origins lie in Fauconnier's mental space theory where mental spaces are defined as "very partial assemblies constructed as we think and talk for purposes of local understanding and action" (Fauconnier, 2007: 351). These mental spaces and the relations between them create a conceptual integration network. "Building an integration network involves setting up mental spaces, matching across spaces, projecting selectively to a blend, locating shared structures, projecting backward to inputs, recruiting new structure to the inputs or the blend, and running various operations in the blend itself" (Fauconnier \& Turner, 2002: 44).

Conceptual integration networks can be represented in the form of a diagram (Fig. 1). A conceptual integration network consists of at least two input spaces, a blended space, and a generic space. This diagram is a depiction of a basic conceptual integration network since some networks can be composed of several input and blended spaces. The mental spaces involved in conceptual integration are the input spaces and the generic space which contains shared elements of the input spaces, and also a new mental space, the blended space - a mental space which incorporates meanings from the generic space and also some new ones which are not present in either the input spaces or the generic space. "Blends contain generic structure captured in the generic space but also contain more specific structure, and they can contain structure that is impossible for the inputs, [...]" (Fauconnier \& Turner, 2002: 47). The input spaces do not project all of their elements to the

\footnotetext{
${ }^{3}$ Many more studies have explored the link between ideologies and advertisement. Judith Williamson's work Decoding Advertisements: Ideology and Meaning in Advertising (2002) explores this as well. Something that many of the authors have come to conclude is that, whether there are prejudices towards women or not, advertisements present people in such uniform manner that they isolate everyone who does not fit into that standard.

${ }^{4}$ Conceptual integration theory or blending theory can account for a number of 'creative' uses of language (e.g. jokes and caricatures).
} 
blended space, they are not simply copied. "Blending involves the establishment of partial mappings between cognitive models in different spaces in the network, and the projection of conceptual structure from space to space" (Coulson \& Oakley, 2000: 178). Rather, the emergent structure is generated by one of three processes: the composition of elements from separate input spaces, the completion of composition through schema induction which involves the unconscious and effortless recruitment of background frames, and elaboration which produces a structure unique to the blend (Evans \& Green, 2006: 409-410).

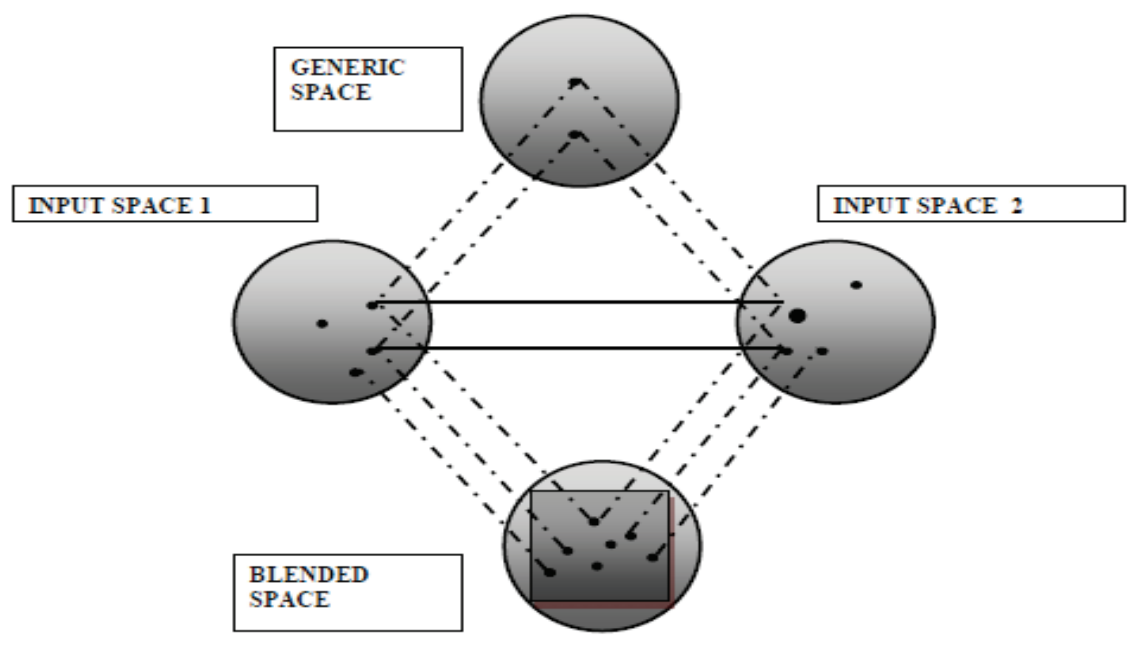

Fig. 1. Conceptual integration network (Fauconnier \& Turner, 2002: 46).

Fauconnier \& Turner (2002) propose that there are a number of different integration networks. Evans \& Green (2006: 426-431) list these as the ones that 'standout': simplex networks, mirror networks, single-scope networks and double-scope networks. Simplex networks have two input spaces, one with the frame containing the roles, and one with the values. ${ }^{5}$ Mirror networks have a common frame shared by all the spaces, including the blended space. In single-scope networks both input spaces have distinct frames and only one of them structures the blended space. Double-scope networks also have input spaces with distinct frames. However, the blended space is a mixture of aspects from both frames.

Conceptual integration is as a process of simplifying complex ideas, presenting the abstract through the concrete. This is achieved through conceptual compres-

\footnotetext{
${ }^{5}$ To deal with ambiguities Fauconnier introduces roles and values. For example, the sentence "The president changes every seven years. "can mean that that person changes (e.g. get a new haircut), or that the person who serves as president changes. The first interpretation is the value (relates to the individual), and the second one is the role (relates to the position); roles and values have different mapping possibilities (Evans and Green, 2006: 381).
} 
sion of conceptual relations called vital relations. Fauconnier \& Turner (2002) distinguish the following vital relations: Change, Identity, Time, Space, Cause - Effect, Part - Whole, Representation, Role, Analogy, Disanalogy, Property, Similarity, Category, Intentionality and Uniqueness. To further clarify vital relations Fauconnier \& Turner (2002) propose a set of optimality principles, and these principles include: Topology Principle, the Pattern Completion Principle, Integration, the Maximization of Vital Relations Principle, the Intensification of Vital Relations Principle, the Web Principle, the Unpacking Principle, the Relevance Principle, the Compression Principle, and Metonymic Tightening.

Since it first appeared, conceptual integration theory has established itself as one of the leading theories because it can account for a wide variety of both linguistic and non-linguistic phenomena. "Blending can be detected in everyday language, idioms, creative thought in mathematics, evolution of socio-cultural models, jokes, advertising, and other aspects of linguistic and nonlinguistic behavior" (Turner \& Fauconnier, 1995: 186). Therefore, it is not surprising that conceptual integration theory has found its application in the study of advertisement.

\section{Conceptual blending in advertising: case studies}

The primary purpose of advertising is to persuade consumers to buy a product. In that sense, Cook stresses that "ads exist to sell, and every member of contemporary industrial society - other than very young children-knows this. Once an ad is identified, such conative components as "buy our product" or "we recommend that" are understood by default" (2001: 172). As Forceville (1996: 68) notices, in a vast variety of advertisements and fierce competition in the world of advertising, advertisers, constrained by the limitations of time or space imposed by different modes of advertising, have to make their advertisements effective and attentiongrabbing. It can be claimed that advertisers tend to exploit their creativity in order to make the advertisements appealing to the consumers but also to rely on shared knowledge of the consumers in order to make them act. ${ }^{6}$

In order to illustrate the applicability of the conceptual integration theory to the study of advertising, we will present the analysis of several advertisements. Instead of stereotypical advertisements on beauty products that are expected in women's magazines we included also an advertisement for financial leasing and an anti-inflammatory ointment, as they are relevant for this market also. This analysis is aimed at showing how the principles designed within conceptual integration theory can account for the construction of the meaning of text-image advertisements, as well as for achieving the main goals of advertising.

${ }^{6}$ Cf. Cook (2001) for similar claims. 


\subsection{Case study one}

Our first case study is the advertisement for Raiffeisen leasing. The advertisement forms a single scope network. The first input space involves our knowledge of the Darwin's theory of evolution. This theory proposes that all species have evolved from simple life forms that have changed over geological time. The central idea of his theory is evolution by natural selection which gradually eliminates inferior species. In the second input space, we have Raiffeisen leasing. Leasing is a form of financial agreement in which a person or a company pays to use the vehicle for a particular period of time. Two distinct processes relate to two input mental spaces that reflect salient aspects of each process: selection process, chain of members of different complexity, where simple forms are placed at the begging and the most complex one at the end of chain.

\section{Evolucija \\ na Leasing}

POKRENITE STVARI NA BOLJE
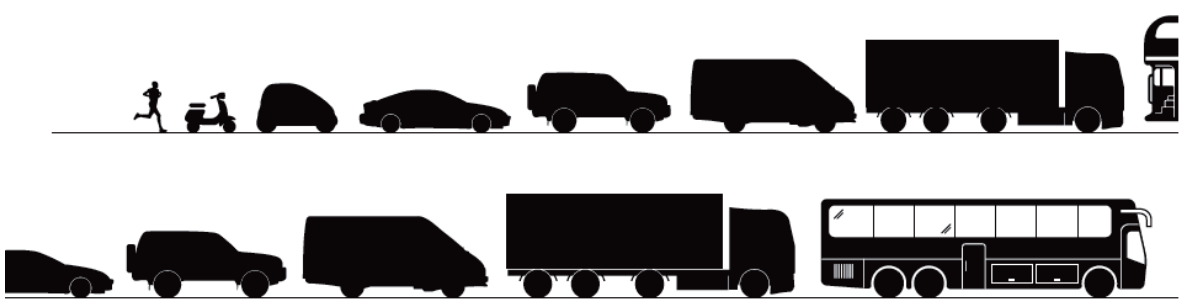

Fig. 2. Raiffeisen bank advertisement

The process of blending consists in partially matching the two input spaces and projecting selectively from these two inputs into the blended space. The blend inherits frame structure from the first input space since in the blend financial leasing is perceived as the process of evolution. The slogan for this particular campaign, Evolution on leasing, move on to better things plays a very important role as from a very small vehicle such as Vespa you can upgrade to a big bus. Vital relation of Analogy connects input spaces and the excellent pictorial representation shows that that financial leasing with this bank is analogous to the process of evolution. In the blend, the first one in the line of motor vehicles is a small Vespa while the last one in the line is a big bus, just like in our conceptualization of the Darwin's theory of evolution we have small, simple organisms at the beginning of 
the chain that over the long period of time were eliminated and replaced by superior species. We know that the process of blending is a remarkable tool of compression over vital relations. In our case study, vital relation of Time is compressed as the process of evolution that takes ages is compressed in short period of time, required to choose a suitable leasing option.

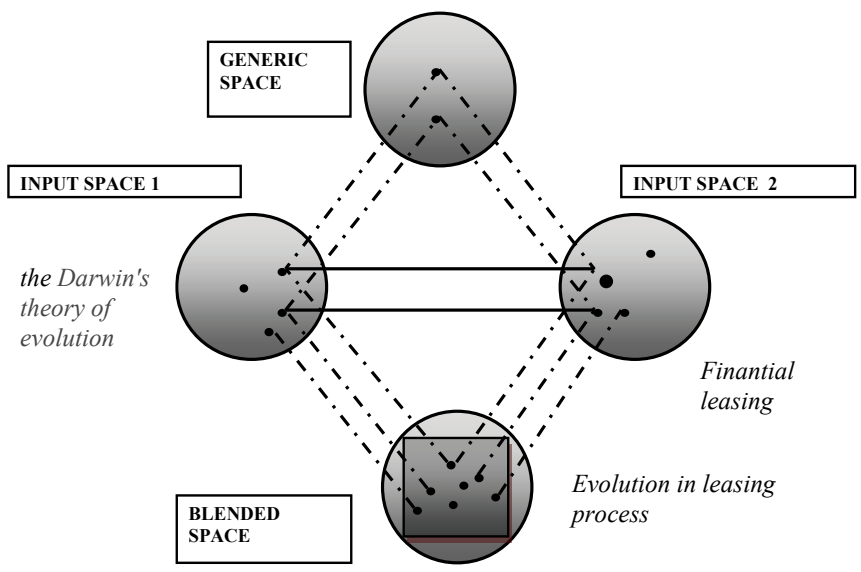

Fig. 3. The conceptual integration network for Raiffeisen bank advertisement

\subsection{Case study two}

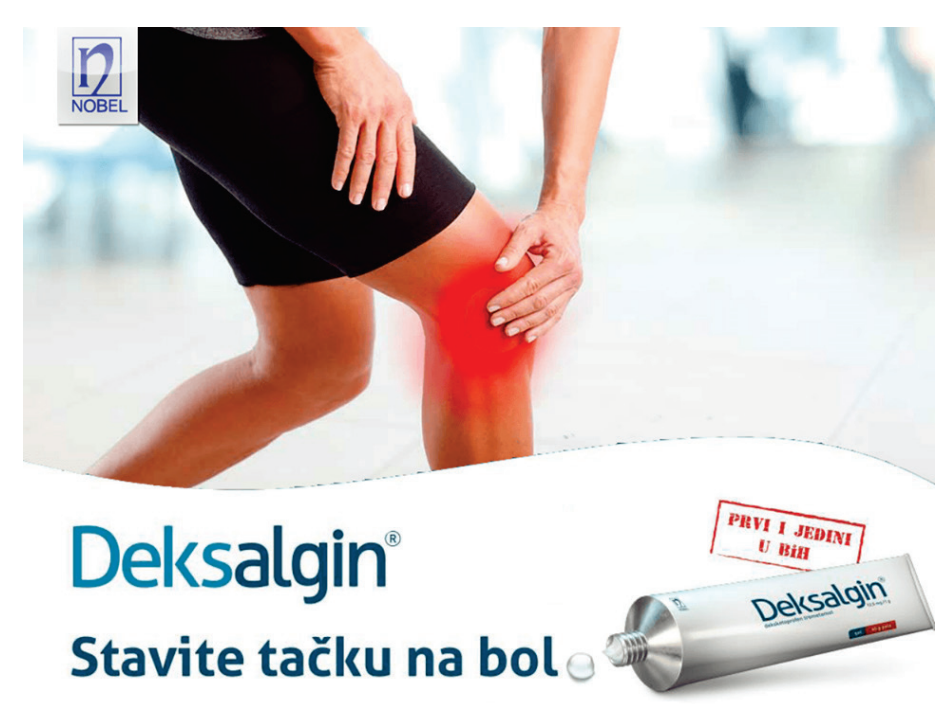

Fig. 5. Deksalgin advertisement 
The second example is the advertisement for Deksalgin ointment. The advertisement forms a double scope network, as inputs in our double-scope network have different organizing frames, but the organizing frame in the blend contains parts of each of these frames as well as a separate emergent structure. Unlike singlescope networks, double-scope networks allow both organizing frames to organize the blend, which becomes fertile ground for conceptual clashes between the frames. Fauconnier and Turner (2002: 131) argue that 'far from blocking the construction of the network, such clashes offer challenges to the imagination; indeed, the resulting blends can be very creative'.

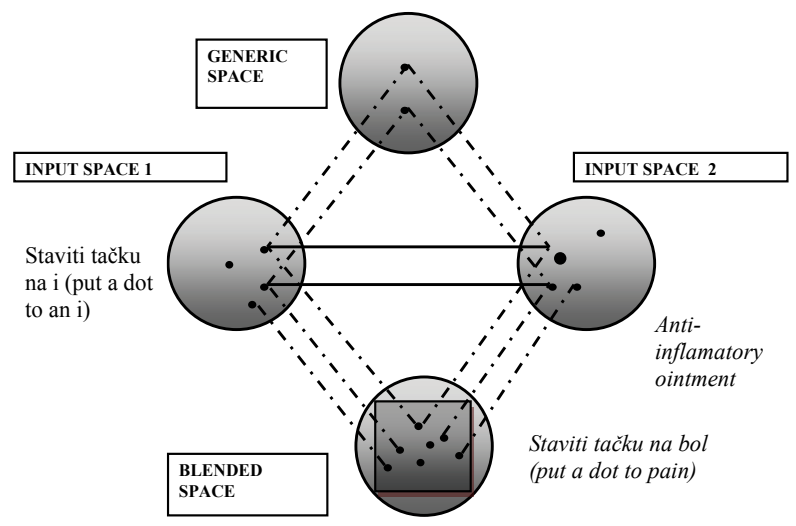

Fig. 4. The conceptual integration network for Deksalgin advertisement

The blend contains modified idiomatic expression staviti tačku na bol 'to put a dot to pain', which is the example of substitution, since the letter $i$ is replaced with the noun bol 'pain'. The author of the advertisement played with polysemy of the

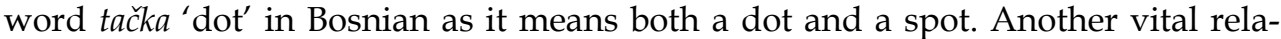
tion, Cause - Effect, serves as a link between the input spaces. In the second input space, the painful spot is treated with anti-inflammatory medication and it is believed that the pain will go away after rubbing in a small amount of ointment. In the first input put space by putting the dot on the letter i, we settle an affair and literary complete the action of writing this symbol. The author of the advertisement exploited the visual similarity of a drop of ointment to a dot.

It can be claimed that using blending in pictorial advertising is particularly advantageous because it allows the use of blended, hybrid images, which are composed from different input spaces into a single hybrid image. Therefore, blending contributes to the creativity and effectiveness of pictorial advertisements. However, this advertisement presents an interpretative puzzle and it order to solve it we have to take into account the linguistic material appearing in the bottom part of the 
picture. ${ }^{7}$ In this particular case, the text presented in the bottom of the picture, is staviti tačku na bol 'to put a dot to pain'. In Barthes's (1981: 29) terms, the text has an anchoring function in that it guides the reader to the intended interpretation. The linguistic elements in these advertisements constrain the possible scenarios that could be developed in the elaboration stage in the blend. Therefore, it helps the reader draw the central meaning and inferences intended by the advertisers. The text, apart from contributing to the creation of the emergent structure in the blend, also helps the reader solve the interpretative puzzle imposed by the pictorial element of the advertisement.

However, it should be noted that "the process of blending is in general invisible to consciousness and detectable only on analysis" (Fauconnier \& Turner, 1994: 3). Therefore, the processing of the hidden messages in advertising is largely unconscious, only occasionally requiring conscious effort to solve the interpretative puzzle by connecting the linguistic and pictorial elements. The process of creating and understanding the new meaning arising in the advertisement takes place in the integration network, the blended space being the most important one. As Fauconnier \& Turner claim, blended spaces "serve as sites of fundamental cognitive work" and "are routinely necessary for constructing central meanings, inferences, and structures, and for motivating emotions" (1994: 3).

\subsection{Case study three}

Our third example is the controversial front cover of the 2015 February edition of Cosmopolitan. This cover creates a double-scope network that consists of two input spaces, generic space and the blend. The first input space contains our knowledge and perception of Cosmopolitan, as the women's magazine that gives beauty and sex advice, presents latest fashion trends, etc. The second input includes the story of a 17-year-old British-Pakistani woman, Shafilea Ahmed, who was suffocated with a plastic bag by her parents in 2003 for refusing an arranged marriage. Both input spaces project their frame structures to the blend. In the blend, the young woman is suffocating, but the film-wrapped issue encourages readers to rip it open and save the woman. This campaign raised a few eyebrows since the image is labelled as disturbing, which is certainly hypocritical as honor killings are almost completely neglected and looked upon as something that should be swept under the carpet. In the unreal scenario in the blend we can rip the film open and save the woman. The blend projects back to input spaces as the idea is to raise awareness about honor killings and thus help save potential victims. Unfortunately, it is not possible to save Shafilea Ahmed. Therefore, women

\footnotetext{
7 Print advertisements, which are said to be of static nature, are usually composed of pictorial and verbal elements. Although there are different views on the function of pictorial and linguistic components and their interaction in such advertisements, generally speaking, as Forceville claims, "linguistic and pictorial information complement each other" (1996: 73).
} 
magazines instead of stereotypical columns related to beady, fashion and sex issues, should cover topics that bother real women and honor killings is one of them.

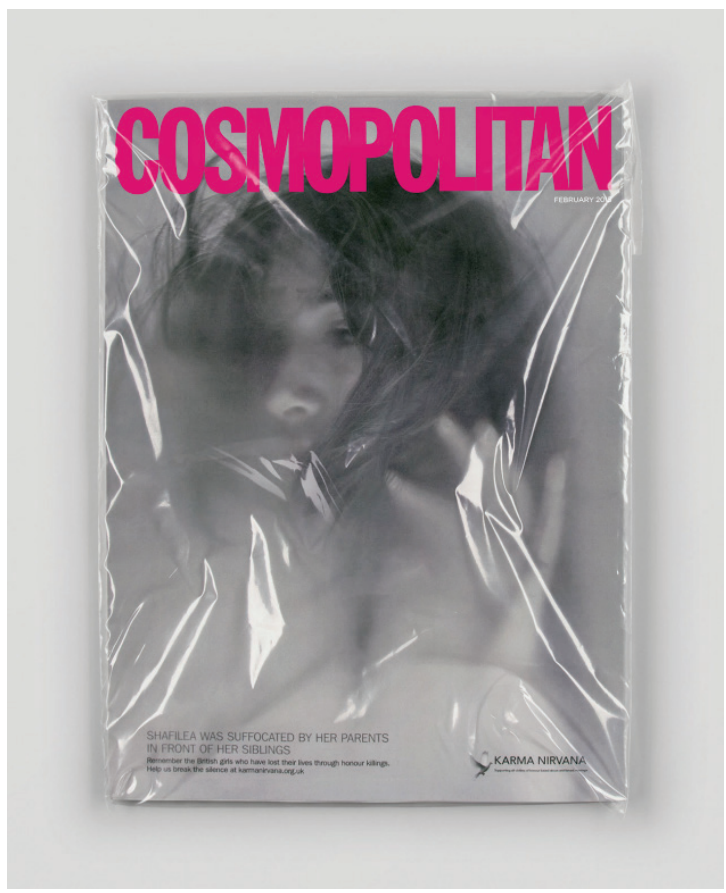

Fig. 6. Cosmopolitan front cover from February 2015

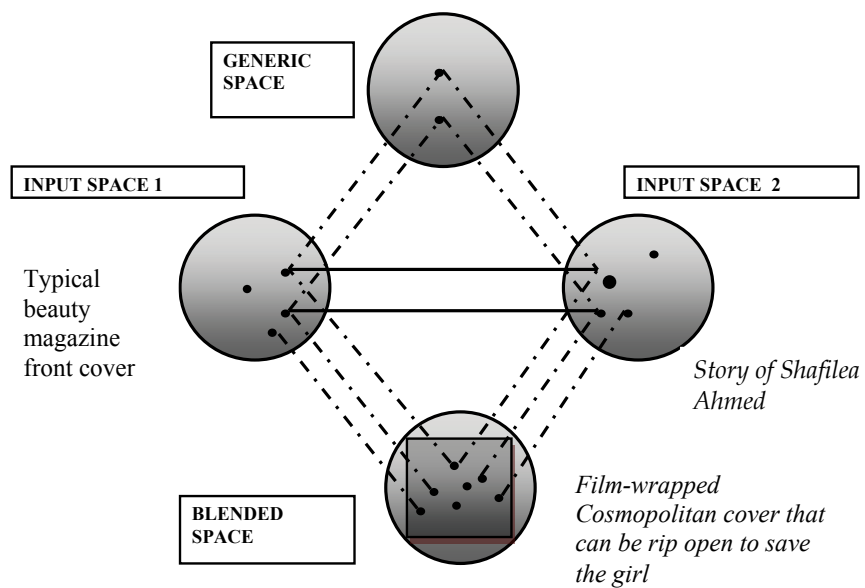

Fig. 7. The conceptual integration network for Cosmopolitan cover 


\section{Concluding remarks}

The analysis of text-image advertisements within the framework of conceptual integration theory presented in the paper shows that the meaning of the advertisements arises in the blended space as a result of a number of intricate mental processes performed over the conceptual integration networks. The processing of the message of these eye-catching blends is largely unconscious, taking place in the integration network. In addition, it can be claimed that conceptual blending in advertising produces a new meaning in the blended space, which is creative, amusing and comprehensible but which, at the same time, also subtly highlights positive characteristics of products and services and which can be powerful enough to make people act upon it. The study has shown that conceptual integration theory can be successfully applied to this field and provide some valuable insights. I can be claimed that, to some extent, conceptual integration theory can explain why advertisements are able to catch our attention and affect our behavior as consumers.

\section{References}

Abuczki, Ágnes (2009). The use of metaphors in advertising: A case study and critical discourse analysis of advertisements in Cosmopolitan. Argumentum 5: 18-24.

Barthes, Roland (1981). Image, Music, Text. Glasgow: Fontana Press.

Beasley, Ron, Marcel Danesi (2002). Persuasive Signs: The Semiotics of Advertising. Berlin: Walter de Gruyter.

Cook, Guy (2001). The Discourse of Advertising. London: Routledge.

Coulson, Seana, Todd Oakley (2000). Blending basics. Cognitive Linguistics 11.3-4: 175-196.

Delibegović Džanić, Nihada, Sanja Berberović (2012). Conceptual integration theory in textimage advertisements. Akbarov, Azamat, Vivian Cook, eds. Contemporary Foreign Language Education: Linking Theory into Practice. Sarajevo: IBU, 559-569.

Evans, Vyvyan, Melanie Green (2006). Cognitive Linguistics: An Introduction. Edinburgh: Edinburgh University Press.

Fairclough, Norman (2001). Language and Power (2nd edn.). Harlow: Longman.

Fauconnier, Gilles (2007). Mental spaces. In Geeraerts, Dirk, Hubert Cuyckens eds. The Oxford Handbook of Cognitive Linguistics Oxford: Oxford University Press, 351-376.

Fauconnier, Gilles, Mark Turner (1994). Conceptual projection and middle spaces. La Jolla, California: Cognitive science technical report 9401.

Fauconnier, Gilles, Mark Turner (2002). The Way We Think: Conceptual Blending and the Mind's Hidden Complexities. New York: Basic Books.

Forceville, Charles (1996). Pictorial Metaphor in Advertising. New York: Routledge.

Hermes, Joke (1995). Reading Women's Magazines: An Analysis of Everyday Media Use. Cambridge: Polity Press.

Hines, Caitlin (1999). Rebaking the pie: The WOMAN AS DESSERT metaphor. Bucholtz, Mary, Albert C. Liang, \& Laurel A. Sutton, eds. Reinventing identities. The gendered self in discourse. New York - Oxford: Oxford University Press, 145-162. 
Kövecses, Zoltán (2002). Metaphor: A Practical Introduction. New York: Oxford University Press.

Lakoff, George, Mark Johnson (1980). Metaphors We Live by. Chicago: University of Chicago Press.

Machin, David, Theo Van Leeuwen (2007). Global Media Discourse: A Critical Introduction. London: Routledge.

McCracken, Ellen (1993). Decoding Women's Magazines: From Mademoiselle to Ms. London: Macmillan.

Tekvar, Sirma Oya (2008). Gender signs in magazine advertisements: A compared semiotic analysis of FHM and Cosmopolitan advertisements [online]. http://mediaeducoandgender.weebly.com/uploads/1/0/3/7/10373263/gender_signs_in_magazine_advertisements-libre.pdf [Accessed April 11th 2017].

Turner, Mark, Gilles Fauconnier (1995). Conceptual integration and formal expression. Metaphor and Symbolic Activity 10.3: 183-204.

Velasco-Sacristán, Marisol, Pedro A. Fuertes-Olivera (2006). Towards a critical cognitivepragmatic approach to gender metaphors in Advertising English. Journal of Pragmatics 38: 1982-2002.

Williamson, Judith (2002). Decoding Advertisements: Ideology and Meaning in Advertising. London: Marion Boyars.

Authors' addresses:

Nihada Delibegović Džanić

Faculty of Humanities and Social Sciences

University of Tuzla

Dr. Tihomila Markovića 1

75000 Tuzla

e-mail: nihada.delibegovic@untz.ba

Alma Žerić

Faculty of Humanities and Social Sciences

University of Sarajevo

71000 Sarajevo

e-mail: alma.zeric@gmail.com

Received: July 12, 2017

Accepted for publication: September 29, 2017 